\title{
Personality and content preferences on social network sites in South Africa
}

\author{
K. Mwabaa ${ }^{\mathrm{a}}$ Y. Saini ${ }^{\mathrm{a}}$ and R. Abratt ${ }^{\mathrm{ab} *}$ \\ ${ }^{a}$ Wits Business School, University of the Witwatersrand, Johannesburg \\ ${ }^{\mathrm{b}}$ Nova Southeastern University, 3301 College Avenue, Fort Lauderdale, FL 33314 \\ *To whom all correspondence should be addressed \\ abratt@nova.edu
}

\begin{abstract}
Worldwide, visual content, such as photos and videos, have increased dramatically on social network sites (SNS), with South Africa being no exception. The purpose of this study was to investigate the relationship between two personality traits - need for cognition and need for affect - and visual and verbal content preference on SNS in South Africa. A survey was conducted and data were obtained from 307 social network site users. The main findings showed that personality does have an influence on SNS users' preference for visual or verbal content. Implications for both theory and practice are discussed.
\end{abstract}

\section{Introduction}

As marketers increasingly integrate social network sites (SNS) as a key promotional tool in the marketing mix, thorough exploration of the factors that impact consumers' usage of these sites is becoming essential (Mangold \& Faulds, 2009). Recently, there has been a rise in visually-dominated content on SNS (Allen, Woodward \& Lamp 2012). The online landscape has become more content rich, and every day, millions of photos and videos are uploaded on SNS such as Facebook, Instagram, Twitter and Pinterest (Meeker \& Wu 2013). In addition, according to Cooper (2013), posts on Facebook that include a photograph have been shown to have higher engagement (for example, 53\% more "likes" and $104 \%$ more comments) than a typical post that only includes text. As a result, companies are starting to see the opportunity of sharing content on SNS that is more visually-oriented and less text based in order to attract the attention of potential consumers (Brennick, 2014; Leposa, 2013) and engage with them through compelling, visual storytelling (Allen, Woodward \& Lamp, 2012).

The growth of SNS for marketing and business therefore highlights the importance of establishing an understanding of SNS and how characteristics, such as personality traits, influence user behaviour and preferences on these sites (Amichai-Hamburger \& Vinitzky, 2010). A significant amount of academic research has been conducted to explore individual's preferences for visual or verbal information (Arcand \& Nantel, 2012; Kim \& Lennon, 2008; Mendelson \& Thorson, 2004; Townsend \& Kahn, 2014). In advertising for example, when evaluating the same advertisement, studies have shown that a consumer that prefers verbal information would process the words in the advertisement, while a consumer that prefers visual information would process the images (Bone \& Ellen, 1992; McQuarrie \& Mick, 2003;
Mitchell, 1986; Sojka \& Giese, 2006). Therefore, although they are exposed to the same advertisement, their responses to the components of the advert (in terms of advertisement recall, purchase intention, etc.) would differ according to their preference for visual or verbal information (Bone \& Ellen, 1992; McQuarrie \& Mick, 2003; Mitchell, 1986; Sojka \& Giese, 2006).

Despite extensive research, an examination of the literature shows that there is a dearth of research on consumer factors that influence preference for a particular type of information processing (visual versus verbal) within the SNS context. Recent studies have indicated that personality traits show the most promise in predicting and understanding SNS usage differences, given that SNS enables interpersonal interaction (Amichai-Hamburger \& Vinitzky, 2010; Chu \& Kim, 2011; Correa, Hinsley \& De Zuniga, 2010; Hughes, Rowe, Batey \& Lee, 2012; Seidman , 2013; Zhong, Hardin \& Sun, 2011). By definition, a trait is a distinctive, relatively durable way in which an individual differs from another (Guilford, 1959). Two particular personality traits - the need for cognition (NFC) and need for affect (NFA) - show particular potential for explaining information processing preference in this study (Sojka \& Giese, 2001; 2006).

The purpose of this paper was to investigate the relationship between personality traits (need for cognition and need for affect) and content preferences (visual and verbal content preference) on social network sites (SNS) in South Africa. There is currently a dearth of scientific studies focusing on understanding how individual consumer factors, such as personality, influence user preferences and behaviour on SNS. In addition, from a practical perspective, this study could provide relevant marketing applications for companies in the development and selection of content on SNS that will be engaging with their consumers. 
Hypotheses development: Personality traits and visual content preference on SNS

Two exploratory studies (Sojka \& Giese, 2001; 2006) found that matching consumer characteristics (need for cognition or need for affect) with the format of the message (verbal or visual) was imperative in attracting attention to and increasing successive processing in print advertisements. Parallels in the processing of affect and visual stimuli suggest that affective processors would react more favourably to visual information than cognitive processors would. For instance, in consumer perception and learning, consumers often group together information (such as a telephone number) into separate "chunks" or segments, rather than try to remember several individual pieces of data (Schiffman, Kanuk \& Wisenblit, 2010).

Previous studies that have compared the processing of images versus words have found that visual stimuli are generally processed in a gestalt manner and words are typically processed in a piecemeal fashion (MacInnis \& Price, 1987; Townsend \& Kahn, 2014). The prior emphasises that the processing of images is usually conducted in a less systematic, faster approach that is more holistic (i.e. processed all at once). For the latter, the processing of verbal stimuli is more deliberate and tends to feel slower or more effortful, given that each word or number must be interpreted individually (Townsend \& Kahn, 2014).

This "chunking" or gestalt processing of visual data is consistent with the holistic nature of affective processing (Childers \& Houston, 1984) which evaluates stimuli in its entirety and deduces for instance that "I just don't like it". Similarly, more visual thinkers have been shown to cope with abstract concepts (which tend to be more visual) more naturally than verbal thinkers (Liu \& Ginther, 1999).

Finally, in advertising, Sojka and Giese (2001) found that individuals with high NFA tend to be more accustomed to deciphering what the visual components in the advertisement represent symbolically. Subsequent research by Sojka and Giese (2006) within the context of print advertising showed statistical and directional evidence for the idea that affective processors have better attitudes towards the advert and brand containing visual stimulus, than those low in affect. Therefore, it is reasonable to conclude that on SNS, users with high NFA would likely be positively associated with a preference for visual content on SNS, given their higher motivation to seek and process affective information. Thus, the following hypothesis is proposed:

H1: There is a positive relationship between the need for affect (NFA) and visual content preference on SNS

Leading from this, in contrast to the holistic nature of affective processing, cognitive processers are more likely to separate or decompose data to identify specific attributes (Mantel \& Kardes, 1999). As a result, it is logical to assume that when viewing different types of content on SNS, individuals with a high need for cognition would prefer not to process visual content, given their predisposition to think rationally and rely on factual, rather than abstract information (Sojka \& Giese, 2006). Thus, the following hypothesis is proposed:

H2. There is a negative relationship between the need for cognition (NFC) and visual content preference on SNS

While visual information has been stressed, not all content on SNS (and marketing material in general) is visual, and therefore it is imperative to investigate the responses of affective and cognitive processors to verbal content.

The Elaboration Likelihood Model (ELM) of persuasion (Petty \& Cacioppo, 1986) has shown the most potential in explaining the relationships between these personality traits and information processing preference (Zhong, Hardin \& Sun, 2011). The model describes attitude change according to a dual process theory, with individuals following either a "peripheral" route or "central" route of persuasion (Petty \& Cacioppo, 1986). Individuals tend to follow the peripheral route in situations where they are not greatly invested or motivated, or do not prefer dealing with complex information (Petty \& Cacioppo, 2012). When evaluating a message or argument, they tend to be influenced by less relevant "peripheral" attributes, such as the appearance or credibility of the person delivering the message, and other less thoughtout heuristics such as moods and emotions (Cacioppo, Petty, Kao \& Rodriguez, 1986). Conversely, for individuals following the central route, active consideration of information is involved and the enjoyment and effort of processing this information is a motivating factor (Cacioppo et al., 1986).

As a result, high NFC individuals are more likely to be swayed by the rationale of the argument and prefer in-depth, logical information to make a decision (Cacioppo \& Petty, 1982). Furthermore, individuals with high NFC were more likely to be influenced by the calibre of arguments (i.e. use the central route of persuasion). Conversely, individuals with low NFC were found to be more likely to use the peripheral route of persuasion (Petty, Cacioppo \& Schumann, 1983) and be swayed by peripheral cues, such as celebrity endorsements, which are less easily depicted in a verbal format compared to a visual format (Sojka \& Giese, 2006).

Therefore, given that individuals with a high NFC are attracted to information that is mentally stimulating and provides them with the opportunity to think and acquire more knowledge, it is reasonable to assume that these SNS users would be specifically drawn to and motivated to process verbal components in SNS content. Therefore, the following hypothesis is proposed:

H3: There is a positive relationship between the need for cognition $(N F C)$ and verbal content preference on SNS

As a result, it follows that the very characteristics of verbal stimuli that individuals with high NFC prefer, will not appeal to individuals with high NFA. Therefore, when looking at verbal information, individuals with high NFA would be less 
inclined to process the verbal components because they prefer to view visual stimuli like pictures (Sojka \& Giese, 2006). Therefore, it is likely that SNS users that have a high NFA are also more likely to dislike verbal content on SNS. The following hypotheses are therefore proposed:

H4: There is a negative relationship between the need for affect (NFA) and verbal content preference on SNS

\section{Methodology}

Respondents were adults (i.e. over 18 years old); had to use at least one SNS (Facebook, Twitter, Instagram, LinkedIn or Pinterest) once a month or more (excluding instant messaging applications such as WhatsApp); and had to work or study in South Africa. This study utilised a convenience nonprobability sampling technique. To test the hypotheses, 307 people participated in the survey in Johannesburg and Cape Town in South Africa. Participants had to be measured to determine whether they were high or low in need for affect and need for cognition. We then proceeded to test the personality traits on the content preferences on SNS.

The research instrument NFA scale consisted of 10 items and was developed by Appel et al., (2012). Preferences for verbal and visual content on SNS, was measured by adapting the Style of Processing (SOP) scale developed by Childers, Houston, and Heckler (1985) which consists of 22 items, with 11 items respectively that measure a visual or verbal processing style. This study utilised two forms of data collection - an online questionnaire which was designed on Qualtrics) and a pen-and-paper self-administered questionnaire through personal direct distribution. Data was collected over a one month period (11 April to 13 May 2016). For the online survey, students were invited to participate in the research via an e-mail which contained a link to the online survey. For the pen-and-paper questionnaire, hard copies of the survey were distributed to students in various classes on campus.

A pilot study was conducted before the main data fieldwork collection and the questionnaire was found to be good but needed to be restructured to make it more visually appealing.Multiple regression analysis and ANOVA were employed and conducted in several steps on SPSS. First, a correlation analysis was conducted to determine whether there are significant correlations between the predictor variables (NFC and NFA) and the outcome variables (visual and verbal content preference on SNS. Thereafter, standard multiple regression analysis was utilised to test the hypotheses

\section{Results}

\section{Social network site usage}

Facebook was the most used social network site in the sample, with $87.2 \%$ of respondents reportedly using it once a month or more often, and more than half $(53.9 \%)$ using it several times a day. Following Facebook in terms of monthly usage was LinkedIn, with $61.2 \%$ of respondents reportedly using it once a month or more. Thereafter, approximately half of the sample reported using Instagram $(54.0 \%)$ and Twitter $(48.5 \%)$ once a month or more. It should be noted that although Instagram had fewer monthly users $(54.0 \%)$ than LinkedIn $(61.2 \%)$, it had triple the amount of respondents reportedly using it several times a day (28\%) compared to LinkedIn (9.2\%). Pinterest was the least used SNS in the sample, with $62.1 \%$ reportedly not using the site at all and less than a third (29.4\%) using it once a month or more.

Regarding length of SNS usage, unsurprisingly most respondents in the sample had been using Facebook, the most established SNS, for five years or longer $(71.8 \%)$, followed by the other older SNS Twitter (19.9\%) and LinkedIn $(14.1 \%)$. For the newer SNS, just under third of the sample used Instagram (32.9\%) and Pinterest $(28.3 \%)$ for less than 2 years.

Mobile phones have become one of the most popular ways to access the internet in South Africa, particularly for social network sites. For instance, according to a 2016 report by World Wide Worx and Fuseware on the South African Social Media Landscape (van Zyl, 2015), of the 13 million Facebook users in the country, the majority (10 million, equating to $77 \%$ of users) use their mobile phone to access the site and 1.4 million $(10.8 \%)$ use tablets. Finally, in accordance with frequency of usage data, Facebook was the most preferred SNS in the sample, with almost half of respondents (49.2\%) mentioning this SNS. This was followed by Instagram; with almost a fifth of the sample (18.6\%) saying they preferred this SNS the most. In response to which SNS was their least favourite, almost a quarter of respondents (23.8\%) reported Twitter followed by Pinterest (19.9\%).

\section{Personality traits and visual content preference on SNS}

To establish the relationship between personality traits (need for cognition and need for affect) and visual content preference on SNS in South Africa, Pearson correlation analysis, analysis of variance (ANOVA) and multiple regression analysis were conducted. Correlation analysis showed that the need for affect (NFA) did in fact have a small positive correlation with visual content preference that was also significant $(r=.12, p<.05)$, as indicated in Table 1 .

Table 1: Pearson correlation matrix among personality traits and visual content preference

\begin{tabular}{llll}
\hline Variable & $\begin{array}{l}\text { Visual } \\
\text { Content } \\
\text { Preference }\end{array}$ & $\begin{array}{l}\text { Need for } \\
\text { cognition } \\
\text { (NFC) }\end{array}$ & $\begin{array}{l}\text { Need for } \\
\text { affect } \\
\text { (NFA) }\end{array}$ \\
\hline $\begin{array}{l}\text { Visual Content } \\
\text { Preference }\end{array}$ & - & & \\
$\begin{array}{l}\text { Need for } \\
\text { cognition (NFC) }\end{array}$ & -.10 & - & \\
$\begin{array}{l}\text { Need for affect } \\
\text { (NFA) }\end{array}$ & $.12^{*}$ & $.21^{* *}$ & - \\
\hline
\end{tabular}

$\mathbf{n = 3 0 7}$ for all correlations tested

*. Correlation is significant at the 0.05 level (2-tailed)

**. Correlation is significant at the 0.01 level (2-tailed) 
Furthermore, multiple regression analysis, as depicted in Table 2, indicated that the need for affect was a significant predictor of visual content preference on SNS $(\beta=.15, p<$ $.05)$. This analysis also showed that NFA had a significant positive association with visual content preference. Therefore, hypothesis 1 , there is a positive relationship between the need for affect (NFA) and visual content preference on SNS was supported.

According to the correlation analysis data in Table 1, it can be deduced that need for cognition (NFC) had a weak, negative correlation with visual content preference, but is only marginally significant at best $(r=-.10, p=.09)$. However, multiple regression analysis as depicted in Table 2 indicated that the need for cognition $(\beta=-.13, p<.05)$ was a significant predictor of visual content preference on SNS.

Table 2: Multiple regression analysis predicting visual content preference from personality traits

\begin{tabular}{llll}
\hline Variable & B & SE & $\boldsymbol{\beta}$ \\
\hline $\begin{array}{l}\text { Constant } \\
\text { Need for cognition }\end{array}$ & 17.45 & 1.93 & \\
(NFC) & -.05 & .02 & $-.13^{*}$ \\
Need for affect & .10 & .04 & $.15^{*}$ \\
(NFA) & & & \\
$\mathrm{F}$ & $4.71^{*}$ & & \\
Adjusted $\mathrm{R}^{2}$ & .02 & & \\
Note: $\mathrm{B}=$ Unstandardised coefficient; $\mathrm{SE}=$ Standard Error; $\beta=$ Standardised \\
coefficient \\
*p $^{\mathrm{p}}$ <.05 (2-tailed)
\end{tabular}

This analysis also showed that NFC had a significant negative association with visual content preference. Therefore, hypothesis 2 that there is a negative relationship between the need for cognition (NFC) and visual content preference on SNS, was supported. Finally, the two personality traits (NFA and NFC) together were found to explain a small, but statistically significant amount of variance in visual content preference on SNS. The total variance explained by this model was approximately $2 \%$, with adjusted $\mathrm{R}^{2}=.02$ and ANOVA results of $F(2,304)=4.71, p=.01$, as shown in Table 2.

\section{Personality traits and verbal content preference on SNS}

The second part of this study was to investigate the relationship between personality traits (need for cognition and need for affect) and verbal content preference on SNS in South Africa. Pearson correlation analysis, analysis of variance (ANOVA) and multiple regression analysis were conducted to investigate the relationships between these variables, as indicated.

The results from the correlation analysis in Table 3 showed that need for cognition (NFC) had a small positive correlation with verbal content preference that was also significant $(r=$ $.21, p<.01)$.
Table 3: Pearson correlation matrix among personality traits and verbal content preference

\begin{tabular}{llll}
\hline Variable & $\begin{array}{l}\text { Verbal } \\
\text { Content } \\
\text { Preference }\end{array}$ & $\begin{array}{l}\text { Need for } \\
\text { cognition } \\
\text { (NFC) }\end{array}$ & $\begin{array}{l}\text { Need for } \\
\text { affect } \\
\text { (NFA) }\end{array}$ \\
\hline $\begin{array}{l}\text { Verbal Content } \\
\text { Preference }\end{array}$ & - & \\
$\begin{array}{l}\text { Need for } \\
\text { cognition (NFC) }\end{array}$ & $.21^{* *}$ & - & \\
$\begin{array}{l}\text { Need for affect } \\
\text { (NFA) }\end{array}$ & .004 & $.21^{* *}$ & - \\
\hline $\mathrm{n}=307$ for all correlations tested \\
*. Correlation is significant at the 0.05 level (2-tailed) \\
**. Correlation is significant at the 0.01 level (2-tailed)
\end{tabular}

Multiple regression analysis as depicted in Table 4 also indicated that need for cognition $(\beta=.22, p<.01)$ was a significant predictor of verbal content preference on SNS. In addition, the analysis showed that preference for verbal content had a significant positive association with NFC, and therefore hypothesis 3 , that there is a positive relationship between the need for cognition (NFC) and verbal content preference on SNS was supported.

Table 4: Multiple regression analysis predicting verbal content preference from personality traits

\begin{tabular}{llll}
\hline Variable & B & SE & $\boldsymbol{\beta}$ \\
\hline $\begin{array}{l}\text { Constant } \\
\text { Need for cognition } \\
\text { (NFC) }\end{array}$ & 12.64 & 1.93 & \\
Need for affect & .09 & .02 & $.22 * *$ \\
(NFA) & -.03 & .04 & -.04 \\
$\mathrm{~F}$ & $7.19^{* *}$ & & \\
Adjusted $\mathrm{R}^{2}$ & .04 & & \\
\hline $\begin{array}{l}\text { Note: } \mathrm{B}=\text { Unstandardised coefficient; SE }=\text { Standard Error; } \beta=\text { Standardised } \\
\text { coefficient } \\
* * \mathrm{p}<.01 \text { (2-tailed) }\end{array}$
\end{tabular}

The correlation analysis data in Table 3 showed that need for affect (NFA) had a very weak correlation with verbal content preference that was not significant $(r=.004, p=.95)$.

Similarly, multiple regression analysis as depicted in Table 4 showed that although NFA did have a weak negative association with verbal content preference as predicted in hypothesis 4 , this relationship was not significant $(\beta=-.04$, $p=.47)$. This personality trait was therefore not a significant predictor of verbal content preference and thus the fourth hypothesis, that there is a negative relationship between the need for affect (NFA) and verbal content preference on SNS was not supported. Finally, of the two personality traits (NFA and NFC), only NFC was found to explain a statistically significant amount of variance in verbal content preference on SNS. As shown in Table 4, the total variance explained by this model was approximately $4 \%$, with adjusted $\mathrm{R}^{2}=.04$ and ANOVA results of $F(2,304)=7.19, p=.001$. 


\section{Discussion}

\section{Personality traits and visual content preference on SNS}

Confirmation of the first hypothesis in the study through multiple regression analysis provides evidence that the more predisposed an individual is to process feelings and approach emotion-inducing experiences (i.e. higher NFA), the more inclined they would be to engage with vivid content on social network sites, such as pictures and videos (i.e. higher visual content preference). Support for the first hypothesis is consistent with findings from previous studies (Sojka \& Giese, 2001; 2006).

Studies in psychology and social communication have shown that a large proportion of meaning in spoken language is obtained from nonverbal indicators such as body language and facial expression, e.g. (Friedman, Prince, Riggio \& DiMatteo, 1980; Nowicki \& Duke, 1994). Given that a large part of this type of communication tends to be appraised and expressed visually (such as facial expressions and body language) (Mayer, DiPaolo \& Salovey,1990), this may give further support to the relationship between need for affect and visual content preference. In conclusion, based on the research findings for hypothesis 1 - as well as academic support from social psychology regarding nonverbal communication and observed SNS trends such as emojis - the need for affect does appear to have a positive relationship with visual content preference on social network sites.

Acceptance of the second hypothesis suggests that the more an individual likes engaging in thinking and cognitively demanding activities (i.e. higher need for cognition), the less they would like to process visual content such as pictures or videos on social network sites (i.e. lower visual content preference). The results of the present study are aligned with a previous similar study in terms of the direction of the predicted relationship (Sojka and Giese, 2001).

From a practical perspective, a potential explanation for the negative relationship between need for cognition and visual content preference in the study could be due to the type of content regularly posted on SNS. A study by Cavalli et al. (2011) on the influence of Facebook on the media habits of university students, found that most students agreed that the content on Facebook is predominantly frivolous and trivial. Similarly, Pew Research Centre reported findings that people sharing too much information about themselves was one the greatest annoyances that Facebook users had with the site (Smith, 2014).

Closely related to these findings is the recent "selfie" phenomenon - the act of taking and posting a self-taken photograph online, particularly on social media (Wickel, 2015). These types of photographs, aided with technological developments such as smartphones and selfie sticks, have helped increase the popularity of image-based SNS such as Instagram, which reportedly has 1000 selfies uploaded every ten seconds (Malcore, 2015). Furthermore, analysis of the top
10 hashtags used on Instagram found that these self-portraits were one of the most popular types of photography shared on the app, with 67 million posted with the hashtag "\#me" in 2013 (Knibbs, 2013).

In light of this, it could therefore be argued that in the context of the rise of highly visual content on social network, much of this content tends to be superficial and somewhat vain, particularly selfies. Therefore, with regards to appealing to certain personality traits, visual content on social network particularly given the frivolous nature of much of it - may not give people with high NFC the mental stimulation and knowledge acquisition they desire. One can therefore conclude that the research results for hypothesis 2 -combined with observed SNS trends such as selfies and theoretical evidence show that the need for cognition does seem to have a negative relationship with visual content preference on social network sites.

\section{Personality traits and verbal content preference on SNS}

Confirmation of the third hypothesis in the study supports the idea that the more predisposed an individual is to seek out mental stimulation and acquire knowledge (i.e. higher NFC), the more they would like to process verbal information on social network sites such as text and links (i.e. higher verbal content preference). Other studies, such as Sojka and Giese (2001), similarly found that high NFC individuals preferred verbal information. Later, in an exploratory experiment, the authors found directional support that cognitive processors may have more positive advertisement and brand attitudes towards verbal advertisements than other types of stimuli, although this was not significant (Sojka \& Giese, 2006).

Further support for the research findings are found in a study by Hughes, Rowe, Batey and Lee (2012), which examined the link between effortful thinking (i.e. NFC), the Big Five personality traits and the use of social network sites Twitter and Facebook. The results showed that need for cognition had a negative correlation with information seeking on Facebook and a positive correlation with information seeking on Twitter. Thus, it is concluded from the study findings, combined with similar findings in prior studies that the need for cognition does appear to have a positive relationship with verbal content preference on social network sites.

Hypothesis 4, which predicted that the more an individual has the need to feel and understand emotions in oneself and others (i.e. higher NFA), the less they would like to process verbal components of SNS (i.e. lower verbal content preference), was not supported in the present research. The lack of support for this relationship was also found in past research. Sojka and Giese (2006) found marginal support for the prediction that high affect individuals will show more negative attitudes towards verbal print advertisements than low affect individuals.

These somewhat contradictory results could potentially be explained by the general pervasiveness of verbal content on 
social network sites. A large amount of content on SNS is still quite text-based, with even highly visual SNS such as Instagram including verbal components such as captions and hashtags to improve understanding of what the uploaded photo means, expand the ease of searching and categorisation of the photos, as well as overall enhancement of the story told (Sornoso, 2014). Thus, despite the "visual revolution" trend seen, words are still essentially the foundational content on which most SNS platforms are based. This present research therefore concluded from the study findings, combined with findings in prior studies and support from reported SNS trends, that there is no conclusive relationship between the need for affect (NFA) and verbal content preference on SNS.

\section{Conclusions}

The aim of this study was to investigate the relationship between personality traits (need for cognition and need for affect) and content preferences (visual and verbal content preference) on social network sites (SNS) in South Africa. Based on the results, one can conclude that personality does have an influence on SNS users' preference for visual or verbal content on these platforms.

\section{Theoretical contributions}

From a theoretical viewpoint, this study adds to current understanding in the consumer behaviour literature by identifying the interrelationship of personality and content preferences on social network sites, particularly within an emerging market context and within the new online media sphere. The key outcome generated from this study is that individual characteristics such as personality traits can, in part, explain differences in SNS content preference. Prior studies, primarily conducted in developed countries such as the USA, have found that various personality traits did have a relationship with various aspects of SNS usage, however, this was not as influential as expected and further investigation of other factors was required (AmichaiHamburger \& Vinitzky, 2010; Chu \& Kim, 2011; Hughes et al., 2012; Zhong et al., 2011). This study, conducted in South Africa, also found personality to have a significant, albeit limited, prediction of differential preferences between visual and verbal content on SNS. Therefore, this research adds to the academic body of knowledge regarding the social network site phenomena, and also extends the generalisability of the research findings beyond a developed country context and into an emerging market context such as South Africa.

Finally, the two particular personality traits investigated in this study - the need for cognition (NFC) and need for affect (NFA) - were found to explain information processing preference in prior exploratory research studies (Sojka \& Giese, 2001; 2006). It should be noted that studies were conducted within the context of traditional above-the-line advertising, such as print media. This present study, which was conducted in the context of social network sites, shows that the differential findings discovered in these previous studies also applied to a newer online media context. In particular, a positive relationship was also found between
NFA and visual stimuli, as well as a positive relationship between NFC and verbal stimuli, as per these past studies (Sojka \& Giese, 2001, 2006); however this study confirmed this in terms of content preference in the SNS environment. Therefore, this current study contributes to the theoretical understanding of these constructs in a new media sphere and offers an academic explanation towards the influences of the observed "visual revolution" trend in SNS.

\section{Practical implications}

In the design of marketing campaigns on SNS, the findings indicate that in order to effectively appeal to individuals who like to approach with emotions (i.e. high NFA), more emphasis should be given to the visual elements (such as pictures and videos) in SNS content. The research has also showed that individuals with a high need for affect do not necessarily dislike the verbal components on social network sites, given that there was almost no relationship between these variables. It is therefore suggested that the amount of verbal content is kept limited in comparison to visual content when an affective appeal is being used on social network sites, in order to optimise engagement.

Furthermore, in light of support from this study for higher NFA being associated with higher visual content preference on SNS, consideration should also be given to using highly recognisable elements, such celebrity endorsements, in branded content. Similarly, in line with global rise of emojis on SNS (Hern, 2015) such as Reactions on Facebook (Greenberg, 2016; Stinson 2016) and branded hashtag emojis on Twitter (Laffertey, 2015; Olanoff, 2015), advertisers should increasingly consider using these in their strategies to increase engagement with SNS users, particularly those with higher NFA. This could include using these animated icons in their messaging and encouraging their consumers to respond to posts using emojis, even within text-based content.

It could also be beneficial for marketers to use different types of content on SNS for certain products or categories, depending on the involvement of the offering. 'Involvement' refers the amount of personal relevance that the purchase or product has for that consumer. Purchases that are very important to the consumers and therefore instigate high problem solving and information processing are defined as high-involvement, with the contrary being the case for lowinvolvement purchases (Schiffman et al., 2010).

Visual content on SNS might be more effective for products such as clothing, impulse purchases (such as chocolate) and luxury goods (such as designer perfume. Furthermore, in accordance with the "visual revolution" observed in SNS, brands in the categories aligned to visual and affective content (i.e. low involvement and hedonic products) could also consider having an increased presence on Instagram, particularly given its recent high growth in South Africa (van Zyl, 2015). Therefore marketing managers in South Africa should evaluate how effective each SNS is for their particular brand, especially considering that the vast majority (over 
$90 \%$ ) of the largest brands in the country reportedly use Twitter for instance (World Wide Worx \& Fuseware, 2014).

It is recommended that verbal content (such as text and links) should be included in order to appeal to consumers who enjoy mental stimulation (i.e. high NFC). In addition, combining the type of stimuli with the underlying personality characteristic might further attract different types of personality processors. Therefore, using a rational, cognitive appeal with descriptive, text-based content might best attract individuals with a high NFC, given both the verbal and cognitive aspects. In addition, it is recommended that visual elements such as pictures and videos be used sparingly for cognitive appeals, given the negative relationship between NFC and visual content preference.

It could also be more advantageous to use verbal content on SNS for products or categories that require consumers to use high problem solving and information processing when making a purchase, particularly given the positive relationship found in the study between NFC and verbal stimuli. Therefore, for high involvement and/or utilitarian products, particularly those with high perceived risk, such as durable goods, automobiles, insurance policies, a house, etc. descriptive verbal content on SNS might be the best way to engage consumers. Further research would however be needed to confirm the relationship between content preference and product category/involvement levels.

\section{References}

Allen, D.J., Woodward \& Lamp, M. 2012. 'Show me a story: How visual content is transforming social media', Public Relations Tactics, 19(5): 16-16.

Amichai-Hamburger, Y. \&Vinitzky G. 2010. 'Social network use and personality', Computers in Human Behavior, 26(6): 1289-1295.

Arcand, M. \& Nantel. J. 2012. 'Uncovering the nature of information processing of men and women online: The comparison of two models using the Think-Aloud Method', Journal of Theoretical and Applied Electronic Commerce Research, 7(2): 106120.

Bone, P.F. \& Ellen, P.S. 1992. 'The generation and consequences of communication-evoked imagery', Journal of Consumer Research, 93-104.

Brennick, J. 2014. 'Add a visual element to your social media strategy’, ABA Marketing \& Sales, 46(3): 43.

Cacioppo, J.T., Gardner, W.L. \& Berntson, G.G. 1999. 'The affect system has parallel and integrative processing components: Form follows function', Journal of Personality and Social Psychology, 76(5): 839-855

Cacioppo, J.T. \& Petty, R.E. 1982. 'The need for cognition', Journal of Personality and Social Psychology, 42(1): 116-131.

Cacioppo, J.T., Petty, R.E. \& Feng Kao, C. 1984. 'The efficient assessment of need for cognition', Journal of Personality Assessment, 48(3): 306-307.
Cacioppo, J.T., Petty, R.E., Kao, C. \& Rodriguez, R. 1986. 'Central and peripheral routes to persuasion: An individual difference perspective', Journal of Personality and Social Psychology, 51(5): 1032-1043.

Cavalli, N., Costa, E.L., Ferri, P., Mangiatordi, A., Micheli, M., Pozzali, A. \& Serenelli, F. 2011. Facebook influence on university students' media habits: qualitative results from a field research, Media in Transition-unstable platforms: The promise and peril of transition, US.

Childers, T.L. 1986. 'Memory for the visual and verbal components of print advertisements', Psychology \& Marketing, 3(3): 137-149.

Childers, T.L. \& Houston, M.J. 1984. 'Conditions for a picturesuperiority effect on consumer memory', Journal of Consumer Research, 643-654.

Childers, T.L., Houston, M.J. \& Heckler, S.E. 1985. 'Measurement of individual differences in visual versus verbal information processing', Journal of Consumer Research, 12(2): 125-134.

Chu, S.-C. \& Kim, Y. 2011. 'Determinants of consumer engagement in electronic word-of-mouth (eWOM) in social networking sites', International Journal of Advertising, 30(1): 47-75.

Cooper, B. 2013. 7 powerful Facebook statistics you should know about. [Online] available: http://www.fastcompany.com/3022301/ work-smart/7-powerful-facebook-statistics-you-should-know-about

Correa, T., Hinsley, A.W. \& De Zuniga, H.G. 2010. 'Who interacts on the web?: The intersection of users' personality and social media use', Computers in Human Behavior, 26(2): 247-253.

Digman, J.M. 1990. 'Personality structure: Emergence of the fivefactor model', Annual Review of Psychology, 41(1): 417-440.

Ellison, N.B. 2007. 'Social network sites: Definition, history, and scholarship', Journal of Computer-Mediated Communication, 13(1):210-230.

Friedman, H.S., Prince, L.M., Riggio, R.E. \& DiMatteo, M.R. 1980. 'Understanding and assessing nonverbal expressiveness: The affective communication test', Journal of Personality and Social Psychology, 39(2): 333.

Greenberg, J. 2016. Advertisers don't like Facebook's reactions. they love them. [Online] available: http://www.wired.com/2016/02/ advertisers-feel-facebooks-new-reactions-\%F0\%9F\%98\%8D/

Hern, A. 2015. Don't know the difference between emoji and emoticons? Let me explain. [Online] available: https://www.theguardian.com/technology/2015/feb/06/differencebetween-emoji-and-emoticons-explained.

Hughes, D.J., Rowe, M., Batey, M. \& Lee, A. 2012. 'A tale of two sites: Twitter vs. Facebook and the personality predictors of social media usage', Computers in Human Behavior, 28(2): 561-569.

Kim, M. \& Lennon, S. 2008. 'The effects of visual and verbal information on attitudes and purchase intentions in internet shopping', Psychology \& Marketing, 25(2): 146-178.

Knibbs, K. 2013. Selfies are now the most popular genre of photo. [Online] available: http://www.digitaltrends.com/social-media/ selfies-are-now-the-most-popular-genre-of-picture-and-in-relatednews-everyones-the-worst/\#:NNHjiqYNmc0ReA 
Laffertey, J. 2015. How the branded hashtag emoji is taking over Twitter. [Online] available: http://www.adweek.com/socialtimes/ how-the-branded-hashtag-emoji-is-taking-over-twitter/630826

Leposa, A. 2013. 'Reputation management - social media gets visual', Hotel Management, 228(3): 42-42.

Liu, Y. \& Ginther, D. 1999. 'Cognitive styles and distance education', Online Journal of Distance Learning Administration, 2(3): 1-19.

MacInnis, D.J. \& Price, L.L. 1987. 'The role of imagery in information processing: Review and extensions', Journal of Consumer Research, 13(4): 473-491.

Maio, G.R. \& Esses, V.M. 2001. 'The need for affect: Individual differences in the motivation to approach or avoid emotions', Journal of Personality, 69(4): 583-614.

Malcore, P. 2015. Selfie obsession: the rise of social media narcissism. [Online] available: http://www.rawhide.org/blog/ infographics/selfie-obsession-the-rise-of-social-media-narcissism/

Mangold, W.G. \& Faulds, D.J. 2009. 'Social media: The new hybrid element of the promotion mix', Business Horizons, 52(4): 357-365.

Mantel, S.P. \& Kardes, F.R. 1999. 'The role of direction of comparison, attribute-based processing, and attitude-based processing in consumer preference', Journal of Consumer Research, 25(4): 335-352.

McQuarrie, E.F. \& Mick, D.G. 2003. 'Visual and verbal rhetorical figures under directed processing versus incidental exposure to advertising', Journal of Consumer Research, 29(4): 579-587.

Meeker, M. \& Wu, L. 2013. Internet trends D11 conference. [Online] available: http://www.kpcb.com/blog/2013-internet-trends

Mendelson, A.L. \& Thorson, E. 2004. 'How verbalizers and visualizers process the newspaper environment', Journal of Communication, 54(3): 474-491.

Mitchell, A.A. 1986. 'The effect of verbal and visual components of advertisements on brand attitudes and attitude toward the advertisement', Journal of Consumer Research, 13(1): 12-24.

Nowicki, S. \& Duke, M.P. 1994. 'Individual differences in the nonverbal communication of affect: The diagnostic analysis of nonverbal accuracy scale', Journal of Nonverbal behavior, 18(1): 935 .

Olanoff, D. 2015. Twitter's custom emojis make their debut as an ad unit with \#ShareACoke. [Online] available: http://techcrunch.com/ 2015/09/17/twitters-custom-emojis-make-their-brands-debut-withshareacoke/

Petty, R. \& Cacioppo, J.T. 2012. Communication and persuasion: Central and peripheral routes to attitude change. New York, Springer Science \& Business Media.

Petty, R.E. \& Cacioppo, J.T. 1986. The elaboration likelihood model of persuasion. New York, Springer.

Petty, R.E., Cacioppo, J.T. \& Schumann, D. 1983. 'Central and peripheral routes to advertising effectiveness: The moderating role of involvement', Journal of Consumer Research, 10(2): 135-146.
Schiffman, L.G., Kanuk, L.L. \& Wisenblit, J. 2010. Consumer behaviour (10 ed.). Upper Saddle River, NJ, Prentice Hall, Pearson.

Seidman, G. 2013. 'Self-presentation and belonging on Facebook: How personality influences social media use and motivations', Personality and Individual Differences, 54(3): 402-407.

Smith, A. 2014. 6 new facts about Facebook. [Online] available: http://www.pewresearch.org/fact-tank/2014/02/03/6-new-factsabout-facebook/

Sojka, J.Z. \& Giese, J.L. 1997. 'Thinking and/or feeling: An examination of interaction between processing styles', Advances in Consumer Research, 24: 438-442.

Sojka, J.Z. \& Giese, J.L. 2001. 'The influence of personality traits on the processing of visual and verbal information', Marketing Letters, 12(1): 91-106.

Sojka, J.Z. \& Giese, J.L. 2006. 'Communicating through pictures and words: Understanding the role of affect and cognition in processing visual and verbal information', Psychology \& Marketing, 23(12): 995-1014.

Sornoso, E. 2014. How to use Instagram hashtags to expand your reach. [Online] available: http://www.socialmediaexaminer.com/ instagram-hashtags/

Stinson, L. 2016. Facebook reactions, the totally redesigned like button, is here. [Online] available: http://www.wired.com/2016/ 02/facebook-reactions-totally-redesigned-like-button/

Townsend, C. \& Kahn, B.E. 2014. 'The "visual preference heuristic": The influence of visual versus verbal depiction on assortment processing, perceived variety, and choice overload', Journal of Consumer Research, 40(5): 993-1015.

Van Zyl, G. 2015. Infographic: SA social media by the numbers. [Online] available: http://www.fin24.com/Tech/Multimedia/ INFOGRAPHIC-SA-social-media-by-the-numbers-20150917

Wickel, T.M. 2015. 'Narcissism and social networking sites: The act of taking selfies', Elon Journal of Undergraduate Research in Communication, 6(1): 5-12.

World Wide Worx \& Fuseware. 2014. South African social media landscape 2015: Executive summary. [Online] available: http://www.fuseware.net/wp-content/uploads/2015/03/ExecSummary-Social-Media-2015.pdf

Zhong, B., Hardin, M. \& Sun, T. 2011. 'Less effortful thinking leads to more social networking? The associations between the use of social network sites and personality traits', Computers in Human Behavior, 27(3): 1265-1271. 